\title{
LAS DIPUTACIONES PERMANENTES Y EL CONTROL SOBRE EL DECRETO-LEY *
}

POR

\author{
JAVIER JIMENEZ CAMPO \\ Universidad Complutense
}

\begin{abstract}
SUMARIO
I. LA POSICIÓN DEL DECRETO-LEY EN EL SISTEMA DE FUENTES DEL DERECHO. II. EL CONTROL PARLAMENTARIO SOBRE EL DECRETO-LEY EN EL ART. 86 DE IA Constitución: 1. Planteamiento general. 2. La tramitación «como proyectos de ley» de los decretos-leyes. 3. El acto parlamentario de «convalidación o derogación».-III. Las Diputaciones Permanentes y el CONTROL SOBRE LOS DECRETOS-LEYES.
\end{abstract}

Estas notas pretenden contribuir a discutir su título. Se trata, pues, de negar el que, en nuestro Derecho, ostenten las Diputaciones Permanentes del Congreso y del Senado, conjuntamente, algún tipo de control sobre las disposiciones legislativas provisionales dictadas por el Gobierno al amparo del artículo 86 de la Constitución. Más claramente: las líneas que siguen buscan - a partir de un sumario planteamiento de la problemática del control parlamentario en este campo- fundamentar que no cabe en el ordenamiento español otra intervención sobre los decretos-leyes, para el caso de disolución o de expiración del mandato del Congreso de los Diputados o de ambas Cámaras, que la que pueda actuarse por la Diputación Permanente del Congreso en virtud de lo dispuesto en los arts. 78.2 y 86.2 de nuestra norma fundamental. Que no existe, por tanto, fundamento constitucional alguno para reconocer en las Diputaciones Permanentes de las Cámaras una potestad legislativa extraordinaria a partir - como se ha dicho- de la asunción por aquéllas de las «competencias propias» de las Cortes Generales en cuanto al control sobre la decretación gubernamental de urgencia.

* El presente trabajo responde, con diversas modificaciones, al contenido de la ponencia expuesta en el seminario que, para profesores y alumnos de doctorado, dirige el profesor don Francisco Rubio Llorente en la Facultad de Derecho de la Universidad Complutense. En el momento de su exposición (abril de 1982) y con posterioridad, el profesor Rubio Llorente ha hecho observaciones y sugerencias que aparecen en el texto y debo ahora agradecer. Asimismo, diferentes aspectos de la problemática que aquí se aborda han quedado más claramente perfilados en las discusiones que sobre ellos he mantenido con el profesor Aragón Reyes. 
La cuestión no creo que tenga, precisamente, un alcance secundario. Ya, con ocasión de la primera disolución constitucional de las Cortes, en enero de 1979, la misma se suscitó en el seno de la Diputación Permanente del Congreso ${ }^{1}, y$, desde entonces, no han faltado valedores de la interpretación que aquí va a intentar discutirse ${ }^{2}$. $Y$ hay que subrayar que hoy no se trata ya sólo de un tema abierto para el debate doctrinal, sino, más urgentemente, de una necesaria crítica del derecho vigente: asumiendo en todo, aparentemente, aquellos dudosos argumentos, y como culminación de un desafortunado desarrollo del art. 86 de la Constitución en diversos extremos, el nuevo Reglamento del Congreso de los Diputados de 24-II-1982 ha venido a consagrar tal competencia legislativa ${ }^{3}$, a crear, por tanto, un nuevo órgano legislativo en el ordenamiento y a distorsionar gravemente, en fin, el sistema constitucional de fuentes del Derecho en un aspecto cuya importancia setá difícil exagerar. $\mathrm{Y}$ ya que no todos los días nos es dado asistir a la emergencia de un nuevo órgano legiferante, parece que la ocasión bien merece una consideración con alguna perspectiva - siquiera brevemente apuntada- acerca de la función del decreto-ley y del sentido de los controles sobre el mismo en el sistema constitucional.

${ }^{1}$ Cfr. J. Salas, Los decretos-leyes en la Constitución española de 1978, Madrid, 1979, págs. $110 \mathrm{y}$ sigs.

${ }^{2} \mathrm{La}$ competencia de las Diputaciones Permanentes para acudir al procedimiento previsto en el art. 86.3 de la Constitución y, en consecuencia, para actuar sobre esta base potestades legislativas ha sido sostenida por G. Peces-Barba en La Constitución española de 1978. Un estudio de derecbo y politica (con la colaboración de L. Prieto Sanchís), Valencia, 1981, págs. 63-64, así como en su aportación al libro La Constitución española de 1978 en la bistoria del constitucionalismo español, de M. Martínez Cuadrado (ed.), Madrid, 1982, págs. 94-95. La misma conclusión mantienen J. Salas, ob. cit., pág. 111, y E. Aja Fernandez, «Consideraciones sobre las comisiones parlamentarias», en Parlamento y sociedad civil, Barcelona, 1980, págs. 133-134. Más cauta la opinión de J. Solé Tura, para quien se trata de una «cuestión compleja que deberá ser objeto de ulterior discusión y precisión» (cfr. «El control parlamentario en el período constituyente y en la Constitución de 1978», en Parlamento y sociedad civil, ob. cit., pág. 45). Aun sin plantear directamente este punto, niega potestad legislativa, en todo caso, a las Diputaciones Permanentes L. Sánchez Agesta, Sistema político de la Constitución española de 1978, Madrid, 1980, pág. 272. Igualmente negativa -aunque apuntando una interpretación que no comparto sobre la aplicación del art. 86,3 en el período entre legislaturas- es la posición de F. J. Bastida, R. Punset e I. de Otto en Lecciones de Derecho Constitucional, vol. I, Oviedo, 1980 , pág. 250.

${ }^{3}$ Según el art. 151.5 del Reglamento, «la Diputación Permanente podrá, en su caso, tramitar como proyectos de ley por el procedimiento de urgencia los decretos-leyes que el Gobierno dicte durante los períodos entre legislaturas». Aunque habrá que volver sobre esta norma en las páginas que siguen, debe observarse desde ahora que la misma, pese a pretender basarse en el citado art. 86.3 de la Constitución, ha alterado el propio tenor de este último precepto, suprimiendo toda referencia al plazo de treinta días con que la disposición constitucional se inicia. Por lo demás $-\mathrm{y}$ pese a que aquí va a negarse tal «competencia» legislativa-, no parece que pueda encontrarse otro sentido, distinto al de su reconocimiento, en el citado precepto reglamentario. Abunda en esta interpretación tanto la parcial reproducción del art. 86.3 en el art. 151.5 como el concepto mismo de «tramitación» que puede extraerse ya de la Constitución (art. 89.1), ya del Reglamento (arts. 128 y 150, entre otros). Que ésta es, parece, la voluntas legislatoris es algo que confirman, en fin, los aludidos debates en la Diputación Permanente tras de la primera disolución de las Cámaras, así como las discusiones en torno a este precepto del Reglamento en la Comisión del Congreso (cfr. Diario de Sesiones de la Comisión de Reglamento, núm. 30, 28-V-1981, pág. 1342). 


\section{LA POSICION DEL DECRETO-LEY EN EL SISTEMA DE FUENTES DEL DERECHO}

Alessandro Pizzorusso y Silvano Tosi han recordado últimamente ${ }^{4}$ cómo la correcta comprensión de cualquier forma política requiere su consideración desde la regulación constitucional de los modos de producción del Derecho, desde el estudio, pues, del sistema de las fuentes normativas. La observación; como se sabe, está ya en Kelsen -antes aún en Jellinek ${ }^{5}$ - y creo, en todo caso, que designa un indispensable hilo conductor para adentrarnos en el estudio de las relaciones entre órganos e instituciones que preconiza nuestra norma fundamental. Unas relaciones que, vistas a través del tamiz de la distribución de competencias normativas, se presentan con ciertos rasgos genéricos, que es preciso recordar ahora para captar la identidad y el sentido de la decretación gubernamental de urgencia.

Se ha dicho ${ }^{6}$ que el sistema de fuentes que entroniza la Constitución de 1978 está caracterizado por su falta de homogeneidad, así como por marcadas tendencias hacia la integración parlamentaria y, en el ámbito de la misma, hacia la ampliación del consenso. En líneas generales, creo que esta observación es certera y que debe especificarse señalando lo siguiente: 1) nuestro ordenamiento presenta un alto grado de complejidad en virtud de las diversas manifestaciones, en el terreno de las fuentes de producción, de los principios pluralista y autonómico reconocidos en los arts. 1.1 y 2 de la Constitución y desarrollados a lo largo de la misma; 2) tal complejidad normativa alcanza un momento básico de integración -en las Cortes Generales, principalmente - aunque no sólo- en lo que se refiere a la articulación territorial del Estado (arts. 149.1, 150 en sus tres apartados, 151.2.4, etc.); 3) pero la «centralidad» parlamentaria ${ }^{7}$ no se agota en el ámbito del Estado-comunidad; también en el área del Estado-persona ha quedado firmemente asentada por el enérgico reconocimiento del principio de legalidad (arts. 9.3, 103.1 y 106.1, entre otros), entendido como reserva absoluta de ley ${ }^{8}$ y con la consiguienie

${ }^{4}$ A. Pizzorusso, «I controlli sul decreto-legge in rapporto al problema della forma di governo», en Politica del Diritto, núms. 2-3, 1981, pág. 302; S. Tosi, «Équilibre et deséquilibre dans la fonction legislative en droit parlementaire comparé», en Parlement et gouvernement. Le partage du pouvoir, Florencia, 1979, págs. 80 y sigs.

${ }_{5} \mathrm{H}$. Kelsen, Teoría general del Estado, México, 1979, pág. 409, y G. Jellinek, Teoría general del Estado, Buenos Aires, 1973, pág. 504.

- A. Predieri, «EI sistema de las fuentes del Derecho», en La Constitución española de 1978, de A. Predieri y E. García de Enterría (eds.), Madrid, 1981, pág. 198.

7 Por «centralidad» parlamentaria no se entiende en el texto sino el momento institutivo básico que ocupan en el sistema las fuentes normativas del Parlamento. De ello no deriva necesariamente, sin embargo, una «posición central» de las Cámaras en el seno del sistema de gobierno ni, menos aún, la hegemonía de aquéllas, cualquiera que sea el sentido que quiera darse a esta expresión. En esta última posición-que aquí no se prejuzga - es, como se sabe, en la que se sitúa un sector de la doctrina italiana, interpretando los nuevos Reglamentos de las Cámaras de 1971 y racionalizando quizá en exceso algunas experiencias de la VII Legislatura en aquel país. Cfr., por todos, A. Manzella, Il Parlamento, Bolonia, 1977, págs. $10 \mathrm{y}$ sigs., y, del mismo autor, «Referendum e centralità del Parlamento», en Referendum, ordine pubblico, Costituzione, Milán, 1978, págs. 172 y sigs.

${ }^{8}$ Cfr. sentencia del Tribunal Constitucional (Sala 2.. ${ }^{a}$ ) de 7-V-1981, en recurso de amparo núm. 238/1981 ( $B O E$ de 21-V-1981, núm. 121). En el mismo sentido se había pro- 
atenuación de la potestad reglamentaria, que apenas si contará con algún espacio en el que actuarse al margen de la necesaria mediación del legislador; 4) en el seno mismo de las Cortes, en fin, el principio de la mayoría simple ha quedado fuertemente excepcionado por la introducción de una fuente peculiar que, como la ley orgánica, expresa tendencias unanimistas, propias de una normación cuasi constitucional, y con notoria trascendencia para la configuración del sistema de gobierno (específicamente para el modo de interacción entre mayoría y oposiciones). Es claro que resulta imposible ahora examinar cada una de estas dimensiones, pero sí debe decirse que las mismas manifiestan algunas condiciones, quizá insuperables, que han incidido decisivamente en nuestro proceso constituyente: una comprensible desconfianza frente a la normación gubernamental, una intensa afirmación del protagonismo normativo de las Cámaras y -evidenciando tendencias comunes a diversos ordenamientos próximos al nuestro - un recelo frente a la aplicación pura y simple del criterio mayoritario, con la consiguiente interposición de «fuentes atípicas» entre la ley y la Constitución. El grado en que estas determinaciones y sus plasmaciones institucionales contraríen o no exigencias difícilmente obviables del Estado contemporáneo y la medida misma en que puedan hallarse en tensión con otros aspectos de la relación Gobierno-Cortes es algo que no va aquí a suscitarse, por más que haya motivos para afirmar unas y otras disfunciones ${ }^{9}$. Sin entrar, por tanto, en el análisis de la coherencia entre sistema político y sistema de fuentes, baste con señalar - para emplazar el problema que debe afrontarse a continuación- que-los rasgos que acaban de mencionarse no quedan ajenos a algunos riesgos que deben reconocerse y que muestran, con bastante claridad, la presencia en nuestro Derecho, aunque no sólo en él, de una tensión básica eñ orden a la distribución orgánica de la función normativa: la necesaria garantía de la eficacia misma de tal función (lo que requerirá intervenciones normativas gubernamentales, junto a las parlamentarias) - y la preocupación por la legitimación de la norma (cuestión que ha de telacionarse con la introducción de mayorías reforzadas). Y los riesgos aludidos deben identificarse tanto en una excesiva - y probable - rigidez del sistema de fuentes (por la hipertrofia de la función legislativa y por los problemáticos contornos de la ley orgánica) cuanto en su posible desarticulación en el seno mismo de la institución parlamentaria. Dejando de lado esta posible última tendencia - que me parece verosímil, si se tiene en cuenta que el ajuste entre creciente necesidad de normación y protagonismo parlamentario

nunciado ya, entre otros, A. Garrorena Morales, El lugar de la ley en la Constitución española, Madrid, 1978, págs. 102 y sigs.

- Para el punto específico de las relaciones ley-reglamento ya se ha destacado la rigidez del sistema constitucional por $M$. Bassols Coma, «Las diversas manifestaciones de la potestad reglamentaria en la Constitución», en La Constitución española y las fuentes del Derecho, vol. I, Madrid, 1979, pág. 337. Claro está que la adecuación de la potestad teglamentaria a las exigencias propias de una Administración «prestacional» dependerá de la interpretación jurisdiccional y, específicamente, de la que vaya realizando el Tribunal Constitucional (cfr. una primera referencia a esta problemática en sentencia 18/1982, de 4 de mayo, sobre conflicto positivo de competencias núms. 220 y 230 , en BOE de 9-VI1982, núm. 137). Para la interpretación por el Tribunal Constitucional Federal alemán del artículo 80 de la Grundgesetz, cfr. M. Fromont, «Le pouvoir réglementaire et le juge dans la République fédérale d'Allemagne», en Mélanges offerts à $M$. Waline, vol. I, París, 1974, páginas $30 \mathrm{y}$ sigs. 
se ha intentado lograr a través del discutible expediente de la «descentralización» legislativa en el interior de las Cámaras-, debe ahora repararse en la incidencia que pueda tener el decreto-ley en el seno de un sistema ciertamente rígido de fuentes como es el nuestro.

Situado en un ordenamiento en el que la interpositio legislatoris es prácticamente ineludible en todo caso y en el contexto de un parlamentarismo «de concertación» (para el que es buen acicate la categoría de la ley orgánica), el decreto-ley puede llegar a desnaturalizarse y a desvirtuar también, como se señalará, la misma potestad legislativa de las Cortes:

A) No me parece, en primer lugar, que esté de más el ponerse en guardia ante una previsible y grave relativización —en parte ya constatable - de la definición misma del decreto-ley como fuente excepcional, cuya adopción se justifica sólo en la existencia de las circunstancias habilitantes invocadas por el art. 86.1 de la Constitución. El concepto jurídico indeterminado que es el caso de «extraordinaria y urgente necesidad», su prácticamente imposible control por el Tribunal Constitucional y los mismos angostos límites en que opera la potestad reglamentaria del Gobierno parecen apuntar -en el marco de un parlamentarismo mayoritario, en cualquiera de sus posibles plasmaciones- a un fácil recurso indiscriminado a esta competencia excepcional, exorbitando así su caracterización constitucional. La temática del «abuso del decreto-ley» - bien conocida en el pasado, así como en otros ordenamientos ${ }^{10}$ - corre el riesgo de hacerse tanto más vigente entre nosotros cuanto que el control sobre estas disposiciones en el art. 86.2 de la Constitución se actúa no ya por ley -lo que significaría, obviamente, colaboración de las minorías e intervención de ambas Cámaras-, sino sólo mediante un trámite de resolución ratificatoria del Congreso de los Diputados en el que es notorio que se afirma resueltamente el continuo Gobierno-mayoría, atenuándose casi por completo el carácter contradictorio y complejo que; con carácter general, tiene la decisión parlamentaria. Así las cosas, el decreto-ley, prácticamente inutilizable hoy como expediente para la «defensa extraordinaria del Estado» ${ }^{11}$, podría terminar configurándose como norma a disposición del Gobierno-mayoría y reabriendo así, paradójicamente, en nuestro ordenamiento la vieja cuestión acerca del concepto de «ley material» y sobre el sentido de la reserva negativamente delimitada en el art. 86.1. Es cierto que este riesgo se atenúa o desaparece cuando el control del decreto-ley no se actúa directamente a través del trámite previsto en el art. 86.2 de la Constitución y sí mediante el procedimiento legislativo mencionado en el número 3 de dicho artículo, pero hay que señalar también que esta última vía ha quedado prácticamente desvirtuada por la regulación que de ella ha hecho el art. 151 del Reglamento del Congreso. Como se indicará en breve, es difícil prever -a salvo una deseable reforma reglamentaria - cualquier operatividad cierta al procedimiento previsto en el art. 86.3.

${ }^{10}$ Cfr., por todos, S. Rodota, «L'abuso dei decreti-legge», en Politica del Diritto, núm. 3, 1980, págs: 380 y sigs., y G. F. Ciaurro, Gli istituti della democrazia, Milán, 1973 , sobre todo págs. 146 y sigs.

${ }_{11}$ A la vista de las materias sustraídas a la normación por decreto-ley, cfr. P. Cruz Villalón, «La protección extraordinaria del Estado», en La Constitución española de 1978, ob. cit., págs. 712-713. 
B) Peto si el decreto-ley puede ser, a tenor de lo que se acaba de apuntar, el cauce a través del que el Gobierno procure una irregular «flexibilización» del sistema de fuentes y una ruptura del marco legal dentro del que deben moverse sus disposiciones, hay algún supuesto en el que la misma decretación de urgencia puede dar ocasión a que se maximalicen las tendencias de centralización parlamentaria - - sta vez en clave «grupocrática»a las que se ha hecho ya una alusión. Se trata, en efecto, de la supuesta competencia de las Diputaciones Permanentes de las Cámaras, para, mediante el recurso al art. 86.3 de la Constitución, tramitar por el procedimiento legislativo un decreto-ley adoptado por el Gobierno en el período entre legislaturas. Tal «competencia», al margen ahora objeciones jurídicas, parece debería entenderse (por más que ello no sea jurídicamente necesario: en las Diputaciones sigue siendo aplicable la regla de la mayoría) en una línea de pancontractualismo generalizado que no sólo se hace patente entre nosotros y que, en este caso, pretendería justificarse en una discutible transferencia de legitimidad desde el órgano Cortes Generales hacia los grupos parlamentarios «representados» en las Diputaciones Permanentes ${ }^{12}$.

Así, si en el primero de los casos que se han examinado la competencia ex art. 86.1 puede instrumentarse, trivializándose la limitación de las circunstancias habilitantes, como medio de normación «ordinaria» por un Gobierno sustentado en una mayoría disciplinada, en el segundo, si se diesen por buenas las tesis que aquí van a negarse, habría que reconocer que la adopción de un decreto-ley en el período entre legislaturas sería el supuesto habilitante para la emergencia en las Diputaciones Permanentes de potestades legislativas. Potestades - habría que añadir - ejercidas por diputados y senadores que, si bien han visto prorrogado su mandato (art. 22.3 del Reglamento del Congreso), ostentan una representatividad cuestionada ante la misma convocatoria de elecciones generales. Pese a todo - y en ese presumible horizonte de integración intrapartidaria-, nos hallaríamos ante «leyes» dotadas de la misma eficacia formal que las adoptadas por las Cortes y dirigidas eventualmente a normar cualesquiera materias.

$Y$, sin embargo, tal «competencia», por más que haya quedado confirmada por el art. 151.5 del Reglamento del Congreso, debe negarse a partir de nuestra norma fundamental. Su defensa es sólo fruto de una incorrecta comprensión del sentido constitucional del art. 86.3, así como de la natura-

12 Aunque es políticamente reveladora, no puede compartirse, desde un punto de vista jurídico-constitucional, la identificación que hace el art. 78.1 constitucional de los miembros de las Diputaciones Permanentes como «representantes» de los grupos parlamentarios. Para el período entre sesiones, tal declaración podría verse como un contrapunto «realista» frente a las afirmaciones clásicas de los arts. 66.1 y 67.2, pero la norma es del todo inconsistente en el supuesto de disolución o expiración del mandato, cuando debe reconocerse que los grupos parlamentarios han desaparecido jurídicamente. En este sentido -extinción del grupo con el término del mandato de la asamblea o con su disolución-, cfr. A. Torres del Moral, «Los grupos parlamentarios», en Revista de Derecbo Político, núm. 9, 1981, pág. 41. Acerca de la problemática general de los grupos parlamentarios en nuestro Derecho, cfr., también, M. Ramírez, «Teoría y práctica del grupo parlamentario», en Revista de Estudios Políticos, núm. 11, págs. 28 y sigs. Sí debe señalarse que esta formulación del art. 78.1 procede de la que ya incorporaba, en términos semejantes, el art. 62 de la Constitución de 1931. 
leza de las Diputaciones Permanentes en el período entre législaturas y de las mismas competencias de éstas según el art. 78.2 de la Constitución.

\section{EL CONTROL PARLAMENTARIO SOBRE EL DECRETO-LEY EN EL ART. 86 DE LA.CONSTITUCION}

1. La delimitación del decreto-ley como disposición «provisional», adoptada en circunstancias excepcionales, ha determinado en el Derecho comparado y en el propio; así como en nuestros antecedentes históricos ${ }^{13}$, la necesaria previsión constitucional de alguna forma de control parlamentario sobre estas normas gubernamentales. Es conocido que tal intervención parlamentaria puede articularse como control en sentido estricto (ordinariamente mediante «resolución» ratificatoria) o, en otros casos, a través de la adopción por las Cámaras de una ley que, suponiendo o no la novación de la fuente gubernamental, proceda a la incorporación de todo o parte del contenido de ésta y a su integración estable en el ordenamiento. La opción por un sistema de control u otro (así como los efectos que al mismo se atribuyan: eficacia ex nunc o ex tunc, por ejemplo) es claro que resulta relevante para el funcionamiento del sistema de gobierno y que dependerá, en cada caso, de la comprensión que quede institucionalizada acerca de las relaciones entre Gobierno y Parlamento. En este punto, el art. 86 de la Constitución -con menos analogías en el ordenamiento italiano de las que a menudo se le reconocen ${ }^{14}$ _ prevé dos vías diferentes de intervención parlamentaria cuya interpretación conjunta debe intentarse, por más que la misma presente algunas dificultades. Dejando, pues, al margen las otras diversas cuestiones de interpretación que este precepto suscita, se tratará a continuación de determinar el posible ajuste entre los trámites previstos en los apartados 2 y 3 del mismo y con vistas a la correcta comprensión de cada uno de ellos.

2. Sobre el art. 86.3 ya se expresaron; en el proceso constituyente, algu-

${ }^{13}$ La primera previsión en nuestro Derecho histórico de una figura próxima al decreto-ley se encuentra ya en el art. 20 del Proyecto de Constitución preparado por Bravo Murillo en 1852, y que, como se sabe, no llegaría siquiera a ser discutido. Hasta 1923, el decreto-ley no sería reconocido y es más que dudoso que puedan considerarse como tales las disposiciones fundamentadas en el art. 1 del Real Decreto de 15 de septiembre de aquel año (el decreto-ley es, en rigor, normación caracterizada por la excepcionalidad y la provisionalidad, y en el precepto citado se habilitaba al presidente del Directorio para proponer al rey «cuantos decretos convengan a la salud pública, los que tendrán fuerza de ley», al margen de todo control ulterior). Sí aparecían estas disposiciones en el artículo 53 del Anteproyecto de Constitución presentado a la Asamblea Nacional consultiva el 6-VII-1929, así como en el art. 80 de la Constitución de 1931, por más que en este último precepto con rasgos que también desdibujan un tanto la identidad del decreto-ley. Para la configuración de estas disposiciones bajo el sistema de las Leyes Fundamentales, cfr. E. Linde Paniagua, «Ley y Reglamento en la Constitución», en Lecturas sobre la Constitución española, vol. I, Madrid, 1978, págs. 262 y sigs.

${ }^{14}$ El régimen jurídico del decreto-ley entre nosotros apenas si tiene más analogías con el predispuesto en el art. 77 de la Constitución italiana que en lo relativo a la formulación de la cláusula general de habilitación. Sí hay algún parentesco mayor con determinados aspectos de la regulación de las ordenanzas de necesidad (Notverordnungen) en el art. 18 de la Constitución austríaca de 1920, tal y como quedó redactado tras la Ley de revisión de 7-XII-1929 (cfr., sobre todo, los número 4 y 5 de este artículo). 
nas perplejidades. Se propuso su supresión en la Comisión de Asuntos Constitucionales del Congreso y se subrayó su carácter supérfluo en el Senado ${ }^{15}$. No era clara, en efecto, la razón de ser de una norma que, aparentemente, se limitaba a «recordar», con algunas peculiaridades procedimentales, la potestad legislativa de las Cortes en virtud del art. 66.2 de la Constitución. Es muy cierto que la defectuosa redacción, en general, del art. 86 y su escasa sistemática oscurece el sentido de la disposición aludida, pero no lo es menos que este último debe ser determinado y que sólo aquellos equívocos explican, en un sector de la doctrina y en el Reglamento del Congreso, la atribución de competencias a las Diputaciones Permanentes a que se viene aludiendo.

El sentido del art. 86.3 - ya se ha dicho- sólo puede apreciarse si se le enmarca en el contexto en el que aparece situado $y$, específicamente, si se le pone en relación, de una parte, con el carácter de disposición legislativa provisional que ostenta el decreto-ley, y de otra, con el trámite parlamentario de «convalidación o derogación» recogido en el número 2 del mismo artículo. El decreto-ley, en efecto, en tanto que disposición provisional, queda sometido en nuestro ordenamiento a un trámite de ratificación en el plazo de treinta días, durante los cuales el Congreso «habrá de pronunciarse expresamente» si se quiere evitar la decadencia de la norma gubernamental. Pero el decreto-ley es también disposición con fuerza de ley y perfecta desde su adopción por el Gobierno, de modo que su eliminación del ordenamiento - si no se quiere acudir a la vía prevista en el número 2 del art. 86- sólo podrá producirse, de acuerdo con la regla del contrarius actus, mediante una ley adoptada por las Cortes Generales, las que, obviamente, no ven excepcionada su genérica potestad legislativa, sobre cualquier objeto, por el hecho de que decida el Gobierno dictar un decreto-ley. Y, como primera observación, esto es lo que precisamente prevé el último apartado del art. 86: la posibilidad de que las Cortes actúen sus facultades legislativas sobre la materia que ha sido objeto de regulación por el decreto-ley y en el período inmediatamente subsiguiente a la adopción de éste. Ahora bien, ¿no se anula tal interpretación en su misma obviedad?; ¿́por qué razón insertar un precepto constitucional en el que no se haría sino considerar el posible ejercicio de competencias que el Parlamento ostenta en todo momento y con carácter general? En mi opinión, si se quiere reconocer una normatividad propia al artículo 86.3 es necesario reparar en que el precepto que esta disposición incorpora ( las Cortes podrán tramitarlos...») tiene sentido en tanto se vea en él no ya una mera remisión - por sí sola inútil- a la posibilidad, siempre latente, de la legislación, sino, junto a ello, y con mayor alcance, una alternativa para las Cortes y por referencia al número anterior del mismo artículo. Tal alternativa lo es frente al enérgico mandato del art. 86.2 («el Congreso habrá de pronunciarse expresamente...») y significa, por tanto, una vía opcional de intervención parlamentaria sobre el decreto-ley, actuada mediante el ejercicio de potestad legislativa, pero también con un contenido material de control, y ello a la vista tanto de la «provisionalidad» que tipifica

15 Cfr. enmienda núm. 523 del Grupo Parlamentario Mixto del Congreso. También la intervención del senador profesor L. Sánchez Agesta en la Comisión de Constitución de la Segunda Cámara (Diario de Sesiones del Senado, núm. 48, 1978, pág. 2215). 
al decreto-ley como del momento en que se decide emprender aquella tramitación. Y esta conclusión se confirma si se consideran las especialidades procedimentales de este precepto. En el art. 86.3 hay, de una parte, la predisposición de un trámite parlamentario específico («procedimiento de urgencia»), y de otra, la advertencia de que el mismo se inicie en el período durante el cual el decreto-ley puede ser objeto de «convalidación o derogación». Estas peculiaridades procedimentales - junto a la fictio iuris que es el tener por «enmiendas» lo que, en definitiva, no serán sino proposiciones de ley tendentes a la modificación de una norma a la que se califica de «proyecto»- deben interpretarse como previsiones al servicio de la alternativa a que se acaba de aludir. La referencia, en primer lugar, a que «durante el plazo establecido en el apartado anterior» se inicie un procedimiento legislativo sólo tiene sentido si se repara en que estamos ante un trámite que posee también efectos materiales de control, porque la provisionalidad del decreto-ley requiere una definición parlamentaria sobre el mismo en el plazo de treinta días y carecería de todo significado este «sometimiento» a plazo si la disposición del Gobierno hubiese sido ya objeto de ratificación por el Congreso. Lo que la Constitución está previendo aquí es el que, durante el mismo plazo a lo largo del que el decreto-ley debe ser objeto de «convalidación o derogación», decidan las Cortes entrar a modificarlo, y ello como opción frente al procedimiento mismo de ratificación expresa. Modificación legislativa que, por lo demás, se tramitará a través del procedimiento de urgencia. $Y$ en este último punto cabrían, quizá, dos diferentes interpretaciones. O bien la «urgencia» que tiene en cuenta el art. 86.3 hay que referirla a la provisionalidad del decreto-ley, o bien se la entiende en conexión con la misma urgencia que tipifica, en el art. 86.1, a la necesidad que ha habilitado excepcionalmente al Gobierno para adoptarlo. Me inclino por esta segunda interpretación (vinculación de la urgencia ex art. 86.3 con la urgencia sustantiva prevista en el número 1 del mismo artículo) en virtud de dos consideraciones. En primer lugar, porque si la referencia fuese a la provisionalidad del decreto-ley, esto significaría que la Constitución pretende aquí el que en los treinta días señalados no sólo se inicie, sino que culmine la íntegra tramitación de aquél como «proyecto de ley», posibilidad que debe rechazarse por impracticable ${ }^{16}$. En segundo lugar, porque si se aceptase la primera de las hipótesis apuntadas, de nuevo estaríamos devaluando todo sentido normativo del art. 86.3 y confirmando su futilidad: tal norma, en este caso, sólo consideraría la eventualidad de una legislación sobre el objeto del decreto-ley y subsiguiente al mismo, pero que - debiendo adoptarse en treinta días - para nada excepcionaría la exigencia de una ratificación expresa, so pena de decadencia (y esta excepción

${ }^{16} \mathrm{La}$ imposibilidad de culminar en treinta días la tramitación completa de una ley ha sido también destacada por O. Alzaga Villaamil, La Constitución española de 1978, Madrid, 1979, pág. 560, y por E. García de Enterría y T.-R. Fernández, Curso de Derecho Administrativo, vol. I, Madrid, 1980, págs. 144-145. Que tal hipótesis resulta prácticamente irrealizable es algo que puede decirse no sólo a la vista del actual Reglamento del Congreso (arts. 109 y sigs. en relación con los arts. 93 y 94), sino también en términos de lege ferenda (cfr. art. 90.3 de la Constitución). Así las cosas, es necesario proceder a una interptetación sistemática y razonable de la noción de «tramitación» utilizada por el art. 86.3 y ver en ella - con los efectos que se indican en el texto- una referencia a la iniciación del trámite legislativo y no ya a su íntegro desarrollo. 
-alternatividad — es, como se ha indicado, la única que puede dar un sentido al enunciado potestativo del art. 86.3).

$\mathrm{La}$ «posibilidad» que abre así el art. 86.3 no es la de que las Cortes actúen su potestad legislativa - lo que sería del todo ocioso-, sino la de que, actuando tal facultad, pùeda obviarse por las Cámaras el trámite de ratificación expresa en el número 2 del mismo artículo. Ahora bien, como nada asegura que culmine en algún momento el procedimiento legislativo así iniciado y como carece de sentido cualquier pretendida «prolongación» de la provisionalidad del decreto-ley hasta su término eventual, no hay sino que constatar aquí que estamos ante una vía de ratificación tácita del decreto-ley por la decisión misma de emprender sobre el mismo un procedimiento legislativo. Pese a las objeciones que, a primera vista, pudiesen adelantarse a tal conclusión ${ }^{17}$, creo que es éste el único modo de entender el significado del artículo 86.3 en términos no meramente reiterativos, así como de ver en el mismo una conveniente flexibilización de los controles parlamentarios sobre el decreto-ley. La norma del art. 86.3 es, sí, norma procedimental y, en cuanto tal, incompleta (se integra con el fondo competencial del art. 66.2), pero norma también cuyo significado sólo se alcanza por referencia a la imposición de un pronunciamiento expreso del Congreso en el número anterior y mediante la cual pueden las Cámaras - sin novar, en sentido riguroso, la fuente gubernamental ${ }^{18}$ - intervenir de un modo más matizado sobre la decretación de urgencia ${ }^{19}$.

${ }^{17}$ No es objeción la que constata que el art. 86.2 requiere pronunciamiento expreso del Congreso, porque precisamente aquí se interpreta la norma potestativa del número siguiente como eventual excepción a tal intervención. Un reparo de más incidencia podría adelantarse señalando que, de este modo, un Gobierno presuntamente minoritario podría eludir el control parlamentario del art. 86.2 con sólo incoar un procedimiento de modificación del decreto-ley a partir del art. 86.3, pero tal objeción se desvanece si se tiene en cuenta que la opción por una u otra vía de intervención parlamentaria habrá de ser objeto, en todo caso, de decisión mayoritaria de la Cámara. Decisión mayoritaria que, es cierto, no implica un pronunciamiento pleno y resuelto sobre el decreto-ley en términos positivos, pero que, vista en el contexto general del art. 86, sí lleva implícita la confirmación de aquél al desistir de una vía que, como la del número 2 de este precepto, podría culminar en la eliminación total de la disposición gubernamental. Resultaría paradófico el que -una vez que la Cámara ha considerado necesaria la permanencia del decreto-ley, por más que con objeciones- éste decayese al término de un plazo en el que parece notoria la imposibilidad de perfeccionar la ley. Y téngase en cuenta que esta admisibilidad constitucional de una ratificación tácita - por hechos concluyentes- en nada confirma la supuesta existencia (que no creo posible) de una ratificación "presunta» por el mero transcurso de treinta días y el silencio del Congreso. Admitir este tipo de «convalidación» sí sería invertir la condición de provisionalidad que define al decretoley. Por lo demás, la ratificación por la decisión de tramitar ex art. 86.3 es claro que sólo corresponde, frente a lo que en algún caso se ha dicho, al Congreso. No hay, por tanto, posibilidad aquí de una atípica ratificación por el Senado, y ello teniendo en cuenta que es esta Cámara la que, en su caso, debe iniçiar el procedimiento legislativo sobre lo que la Constitución considera «proyecto».

${ }_{18}$ El efecto derogatorio de la ley eventualmente adoptada en virtud del art. 86.3 (ley que, obviamente, no podrá tener por objeto exclusivo la producción de tal efecto, puesto que para ello está el trámite del número anterior) se producirá aun en el caso de aquellas de sus disposiciones que reiteren las del decreto-ley. Como acto de normación sucesiva e independiente de la disposición gubernamental, esta ley no podrá retrotraer sus efectos hasta la fecha en que el decreto-ley entró en vigor. Cuestión muy diferente es la que se plantearía en aplicación del art. 86.2 si fuese «ley» el acto mediante el que el Congreso 
3. Por lo demás, el procedimiento previsto en el último apartado del artículo 86 muestra su sentido más claramente si se le compara con el regulado en el número anterior. Jurídicamente $-\mathrm{y}$ pese a las poco correctas expresiones que se han empleado ${ }^{20}$-, estamos aquí ante un trámite de ratificación, formalizado en una resolución del Congreso de los Diputados. Aunque sí se trata de un acto con fuerza de ley a efectos de su hipotética fiscalización por el Tribunal Constitucional (art. 27.2.b de la Ley Orgánica 2/1979, de 3 de octubre), debe negarse que estemos ante una ley ${ }^{21}$. Y el que no sea ley el acto mediante el que el Congreso «convalida» o «deroga» la norma gubernamental es algo que se desprende claramente de las siguientes consideraciones: 1) en primer lugar, porque el acto es meramente unicameral y porque con ocasión del mismo no ostentan los diputados poder alguno de enmienda ${ }^{2}$; 2) porque, sobre todo, si admitiésemos que lo que se adopta es una ley, quedaría por completo desvirtuado el precepto (art. 86.1) que sustrae ciertas materias a la normación mediante decreto-ley: una vez «convalidado» éste,

ratifica la norma gubernamental. En tal supuesto, como se indica más adelante, sería inevitable la conversión de aquél por la falta de independencia normativa en la ley presupuestamente adoptada.

${ }_{19} \mathrm{Me}$ parece claro que el procedimiento de control parlamentario sobre el decreto-ley gana en elasticidad si se considera, como aquí se ha hecho, la existencia de una alternativa entre los números 2 y 3 del art. 86 y la apertura, por tanto, de una vía para que las Cortes, en cierto modo, colaboren en una normación que se sigue presentando como urgente. El carácter necesariamente sucesivo de la tramitación como ley - por el que ha optado, confirmando una práctica convencional desde 1979, el art. 151.4 del Reglamentosólo será más favorable al Gobierno y a la permanencia de sus disposiciones en ciertos casos y no es difícil imaginar circunstancias parlamentarias en que, por esta misma rigi$\mathrm{dez}$, se inviertan sus aparentes efectos «protectores». A favor también de la alternatividad de una y otra vía se han pronunciado, entre otros, O. Alzaga Villaamil, ob. cit., pág. 560; E. García de Enterría y T.-R. Fernández, ob. cit., pág. 144; F. Garrido Falla, Comentarios a la Constitución, Madrid, 1980, pág. 877, y E. Linde Paniagua, ob. cit., pág. 268. En contra, J. Salas, ob. cit., pág. 108. Debe decirse, por lo demás, que, afirmado el carácter alternativo del trámite ex art. 86.3 respecto del previsto en el número anterior, no se prejuzga aquí la posibilidad de que, habiéndose optado por este último, se acuda a aquél tras de la «convalidación» o, incluso, tras de la «derogación» del decreto-ley. Que tal posibilidad quede abierta - por más que no esté aquí el sentido del art. 86.3- es algo que depende sólo del Reglamento.

${ }_{20}$ Para la crítica a las expresiones utilizadas por el art. 86.2, cfr. J. Salas, ob. cit.. págs. 91 y sigs. En cuanto al concepto de ratificación, cfr. C. Mortati, Istituzioni di diritto pubblico, vol. I, Padua, 1975, pág. 290.

${ }^{21}$ En contra -afirmando el carácter de «ley» del acto-, E. García de Enterría y T.-R. Fernández, ob. cit., pág. 145; A. Predieri, ob. cit., pág. 183, y J. Salas, ob. cit., pág. 92.

${ }_{22}$ Sobre la anomalía de una «ley» unicameral, cfr. E. Linde Paniagua, ob cit., pág. 267. Sin embargo, para Salas, no hay aquí especial dificultad, puesto que, señala, no otra cosa ocurrirá en cualquier otra ley que, vetada o enmendada por el Senado, sea finalmente adoptada por la sola decisión del Congreso; «en este supuesto -indica- es obvio que la ley es en realidad producto de la voluntad de una sola de las Cámaras» (ob. cit., página 94). No pretendo reabrir la polémica entre racionalismo y voluntarismo, pero sí señalar que este tipo de argumentos prueban demasiado (tampoco la mayoría del Congreso - a cuya exclusiva voluntad puede deberse «en realidad» la ley- es, en nuestro Derecho, órgano legislativo). Por otra parte, y como argumento menor, pero no indiferente, el carácter de ley del acto dictado, ex art. 86.2, debiera ser aún menos argumentable para quienes defienden, en contra de lo que aquí se ha sostenido, el carácter necesariamente sucesivo de la eventual tramitación a partir del número 3 de este artículo ( «las Cortes podrán tramitarlos», señala, refiriéndose a los decretos-leyes, este apartado). 
se produciría su desaparición del ordenamiento, quedando convertido en ley formal y sin posibilidad, por consiguiente, de que el Tribunal Constitucional controlase lo que originariamente pudo haber consistido en una abierta extralimitación del Gobierno en violación del art. 86.1 de la Constitución. En rigor, lo que adoptaría en tal caso el Congreso sería un auténtico bill de indemnidad $^{23}$. Tal consecuencia sería jurídica y políticamente inadmisible; hay que subrayar que existe una estrecha vinculación entre los dos primeros apartados del art. 86: precisamente porque el acto es unicameral y porque en él se atenúan los procedimientos garantizadores propios mediante los que el Parlamento, con carácter general, decide tiene sentido que el acto de ratificación no sea ley en modo alguno o, lo que es lo mismo, que también pesen sobre la mayoría gubernamental los límites objetivos del art. 86.1 ${ }^{24}$.

\section{LAS DIPUTACIONES PERMANENTES Y EL CONTROL SOBRE LOS DECRETOS-LEYES}

A partir de las consideraciones anteriores es ya posible encarar con alguna precisión el punto que da título a este trabajo. El art. 78.2 de la Constitución atribuye a las Diputaciones Permanentes (el plural, como se verá, está aquí incorrectamente empleado) la tarea de «asumir las facultades que correspondan a las Cámaras, de acuerdo con los arts. 86 y 116, en caso de que éstas hubieran sido disueltas o hubiere expirado su mandato». Estas competencias - junto a la de instar una reunión en sesión extraordinaria de las Cámaras (art. 73.2) y a la escasamente precisa de «velar por los poderes» de las mismas- constituyen el elenco funcional que identifica jurídicamente a las Diputaciones, y sobre el que habrá que volver, brevemente, más adelante. Por lo pronto, es preciso centrarse en la citada remisión del art. 78.2 a las facultades que correspondan a las Cámaras «de acuerdo» con el art. 86, porque

${ }^{23}$ Que una ley de ratificación convierte al acto objeto de la misma fue ya claramente argumentado por Santi Romano en su Saggio di una teoria sulle leggi di approvazione (recogido hoy en Scritti minori, vol. I, Milán, 1950, en especial pág. 80). En el ordenamiento italiano, y al no encontrar el decreto-ley límites materiales (a salvo su incidencía en materia constitucional), la generalidad de la doctrina sí entiende que la ley dictada en virtud del art. 77 de la Constitución produce la conversión de la disposición gubernamental (cfr., por todos, G. Viesti, Il decreto-legge, Nápoles, 1967, págs. 154 y sigs., y V. di Ciolo, Questioni in tema di decreti-legge, Milán, 1970, págs. 291 y sigs.). Para nuestro Derecho, sin embargo, sostener que es «ley» el acto de ratificación impediría toda futura fiscalización por el Tribunal Constitucional sobre posibles violaciones del art. 86.1, ya que «el legislador no es aquel por cuya autoridad se hizo inicialmente la ley, sino aquel por cuya autoridad continúan ahora siendo leyes» (T. Hobbes, Leviatán, XXVI, 5).

${ }^{24}$ Por 10 demás $-y$ aunque no puede ser ahora planteado en profundidad este aspecto-, debe también indicarse que el mismo carácter del acto de «convalidación o derogación», como manifestación de control, se desdibuja un tanto si se tiene en cuenta la impronta aquí del continuo Gobierno-mayoría y la nota de alteridad que la idea misma $\mathrm{de}$ control requiere (sobre este punto, cfr. S. Galeotti, Introduzione alla teoria dei controlli costituzionali, Milán, 1963, págs. 77-78). Más que ante un acto de control en sentido estricto, estaríamos aquí ante una manifestación de la llamada función de «orientación política». 
es en la relación entre estos preceptos —en el marco del sistema general de la Constitución- donde habrá de indagarse la respuesta a algunas de las dificultades de interpretación a las que se ha hecho ya referencia.

La extraordinaria y urgente necesidad que legitima la competencia gubernamental para adoptar decretos-leyes no queda, obviamente, en suspenso ni por el hecho de que las Cámaras no estén reunidas ni porque haya expirado su mandato o se encuentren disueltas. $Y$ en previsión de que las circunstancias requieran el ejercicio de esta legislación extraordinaria, el ordenamiento mantiene los necesarios controles y garantías: convocatoria de las Cámaras por las Diputaciones Permanentes cuando el decreto-ley se haya dictado en el período entre sesiones (art. 73.2) y a efecto de que se actúen los controles ordinarios sobre la disposición del Gobierno o bien ejercicio del control mismo por estos últimos órganos en caso de disolución o decadencia del mandato. De este modo, la propia Constitución reconoce y da un cauce a la necesidad, asegurando la continuidad en el ejercicio de las funciones estatales aun cuando uno de los órganos fundamentales se encuentre imposibilitado de actuar. Ninguna duda, pues, en el caso de disolución o expiración del mandato, respecto de las competencias de la Diputación Permanente del Congreso de los Diputados: a ella le corresponderá, de acuerdo con lo previsto en el artículo 86.2, el otorgar o no la ratificación («convalidación o derogación») al decreto-ley y la participación, por tanto, en esta actividad de orientación política en que se materializa el acto de control. Pero aquí termina la intervención de este órgano por referencia a la decretación de urgencia. No cabe, en particular, reconocerle competencia para acudir a la vía del art. $86.3 \mathrm{ni}$, en consecuencia, para iniciar tramitación alguna que pueda culminar en la adopción de una ley. $Y$ esta inexistencia de potestad legislativa, ni ordinaria ni extraordinaria, en la Diputación Permanente —en las Diputaciones, mejor, puesto que, caso de admitirse, el acto debiera ser complejo- se hace evidente, según creo, tanto a partir de las consideraciones que anteceden como de acuerdo con algunas observaciones más que se harán a continuación.

Con carácter general, las tesis que vienen abogando por el reconocimiento de esta «competencia» se sustentan, exclusivamente, en argumentos literales extraídos del art. 78.2. «In claris non fit interpretatio», dice un viejo -e ingenuo- brocardo, y, de acuerdo con él, la conclusión parece terminante: aquel precepto reconoce a las Diputaciones Permanentes las facultades que correspondan a las Cámaras de acuerdo con el art. 86; es así que en el número 3 de este artículo se hace referencia a la potestad legislativa de las Cortes, de donde resulta que tal competencia - objeto también de la genérica remisión del art. 78.2 - se integraría entre las propias de la Diputación Permanente ${ }^{25}$. En apoyo, por lo demás, de esta tesis estarían las propias incorrecciones lingüísticas - ya aludidas - del mismo art. 78.2 (empleo indiferenciado del plural para aludir a las facultades de las Diputaciones y para referirse, incluso, a las competencias de «las Cámaras» en virtud del art. 86), así como algunas interpretaciones, que creo confusas, acerca de la supuesta

${ }^{2 s}$ Así, Salas, ob. cit., pág. 111; Peces-Barba, La Constitución española, ob. cit., pág. 63, y Aja, ob. cit., pág. 133 . 
condición de las Diputaciones como «Cámaras en funciones» ${ }^{26}$. En las líneas que siguen se intentará mostrar el débil fundamento constitucional de estos planteamientos, y ello, en algún caso, apelando a lo que anteriormente se ha anotado en cuanto a la interpretación general del art. 86. Sí debe señalarse, con todo, que algunas de las réplicas que se han adelantado frente a tales tesis - y que coinciden, por tanto, en sus conclusiones, con la que aquí va a mantenerse- no parecen enteramente satisfactorias ni afectan al núcleo básico del problema planteado. En efecto, no resulta en modo alguno concluyente para contradecir que en estos casos ostenten las Diputaciones potestad legislativa la observación de que el art. 86.3 se refiera a «las Cortes» ni tampoco la mera remisión a los arts. $66.2,79$ y 91 . Todos estos preceptos aluden, ciertamente, a las competencias, funcionamiento y actos del órgano Cortes Generales, pero de ellos no se infiere, sin más, negación de la facultad controvertida, porque lo que se trata de saber es precisamente el alcance y límites de la remisión del art. 78.2. Y sigue sin ser del todo decisivo - por más que la observación esté llena de buen sentido- el señalar que extender. dicha remisión «a un punto casi marginal del art. 86 sería pretender basar la potestad legislativa de la Diputación Permanente en un precepto dedicado, precisamente, a la facultad normativa del Gobierno» ${ }^{27}$. Marginal o no, la «competencia» se halla en un precepto al que remite el art. 78.2, y es sobre todo en esta relación internormativa donde - sin desdeñar otras consideraciones- debe centrarse la tarea de interpretación.

1. Una primera dificultad - ya que no objeción jurídica terminantepara la facultad que ha acabado reconociendo el citado art. 151.5 del Reglamento del Congreso ya ha sido expuesta en alguna ocasión y debe ahora recordarse, porque no es en modo alguno irrelevante: existen dudas muy razonables en cuanto a las posibilidades reales de articular un procedimiento complejo como es el legislativo en el ámbito reducido y de extrema simplificación orgánica de la Diputación Permanente. No se trata ya sólo de los propios términos temporales en que la facultad en cuestión habría de actuarse (art. 68.6 de la Constitución), sino de la escasa o nula capacidad de órgano tan restringido para - sin alterar las varias fases del proceso legislativo y, en definitiva, la garantía que el procedimiento asegura - terminar adoptando una ley en el respeto a las reglas y principios constitucionales. La única articulación orgánica de la Diputación que prevé el Reglamento es una Mesa que queda integrada por dos vicepresidentes y dos secretarios —además de por el presidente del Congreso, que lo será también de este órgano- elegidos de entre sus miembros «de acuerdo con lo establecido para la elección de la Mesa del Congreso, adaptado al distinto número de puestos a cubrir» (art. 56, números 1 y 3, del Reglamento). No puede decirse que estemos ante una estructura muy compleja, y aunque nada impide el que la Diputa-

${ }^{26}$ Me refiero a la no infrecuente aplicación de construcciones propias de la prorogatio para el análisis del carácter y competencias de las Diputaciones Permanentes; cfr. por ejemplo, E. Recorder de Casso, «Comentario al art. 78», en Comentarios a la Constitución, ob. cit., págs. 833 y sigs.

${ }_{27}$ Los argumentos citados en el texto han sido expuestos por P. L. Serrano Contreras, "¿Leyes de la Diputación Permanente de las Cortes?», en Revista Española de Derecbo Administrativo, núm. 24, 1980, especialmente págs. 94-95. 
ción nombre alguna «Comisión» o «Ponencias» en su seno, parece claro que el iter legislativo que a partir de ellas habría de desenvolverse adquiere, casi inevitablemente, un pintoresco carácter doméstico en el que no es difícil prever la atenuación del debate y la virtual desaparición de la deliberación. Y en este contexto resulta ciertamente ilusoria - aun aplicada a esta «Cámara en funciones» a la que se diría que quiere aspirarse- la previsión del art. 58 del Reglamento: «Será aplicable a las sesiones de la Diputación Permanente y a su funcionamiento lo establecido para el Pleno en el presente Reglamento.» Podría quizá argüirse la posibilidad que tendría la Diputación de acudir al procedimiento legislativo especial previsto en el art. 150 del Reglamento ( «De la tramitación de un proyecto de ley en lectura única»), pero hay que decir que ni las normas a elaborar habrían de contar, necesariamente, con la «simplicidad» que este precepto requiere ni existen tampoco facilidades para hacer efectivas las garantías que el Reglamento señala para la adopción de una decisión en orden a este tipo de trámite.

2. Sin embargo, en virtud del razonamiento anterior $-\mathrm{y}$ aunque hubiese que dejar por el camino buena parte de las condiciones que tipifican al procedimiento parlamentario-, no queda descartada, en sí misma, la facultad que se cuestiona. La remisión al art. 86 - supuestamente comprensiva de todas las intervenciones parlamentarias en él reseñadas- seguiría estando en pie. Pero tal remisión genérica - esto es lo sustantivo- es sólo aparente. El art. 78.2 declara, sí, que las Diputaciones Permanentes asumirán las facultades que correspondan a las Cámaras «de acuerdo» con el art. 86, y la referencia es jurídicamente irreprochable: «de acuerdo» con el art. $86-$ con su segundo apartado-, se ejerce el control parlamentario sobre el decreto-ley mediante «convalidación o derogación», y esto es lo que propiamente se confiere a la Diputación del Congreso por la Constitución. Pero en modo alguno cabe concluir en que todas las funciones parlamentarias mencionadas en el art. 86 se integran en el ámbito competencial de aquel órgano. Más claramente: las Cortes no ejercen su potestad legislativa en virtud del número 3 de dicho precepto, sino, obviamente, sobre la base del art. 66.2 de la Constitución. En el art. 86.3 no se les reconoce a las Cámaras facultad legislativa alguna, que mal podría quedar atribuida a las Diputaciones por obra del art. 78.2. Lo que hace el art. 86.3 - se ha señalado ya - es algo diferente de una atribución competencial: enlaza determinado efecto sobre el decreto-ley a la decisión que puedan tomar las Cortes de ejercer su genérica potestad legislativa. En el tan repetido último número del art. 86 hay sólo una norma especial - regla de procedimiento y no norma de competencia- en la que se busca, con mayor o con menor fortuna, adecuar el ejercicio de una potestad legislativa insuprimible a las peculiares circunstancias del período que subsigue a la adopción de un decreto-ley. No cabe, pues, hablar, a propósito del art. 78.2, de remisión a facultades que, sencillamente, no están en el precepto al que la remisión se refiere. Nadie sostendrá que, por el hecho de que se haya declarado un estado de alarma, de excepción o de sitio una vez disueltas las Cámaras o expirado su mandato, las Diputaciones Permanentes puedan pasar a ejercer - además de las específicas facultades de control y orientación señaladas en el art. 116 de la Constitución- las potestades legislativas de las Cortes o que aquéllas puedan revisar la misma ley orgánica 
reguladora de tales estados. $\mathrm{Y}$, sin embargo, el razonamiento que se viene criticando valdría también para estos casos: el párrafo primero del art. 116.5 alude expresamente a que el «funcionamiento» de las Cámaras (por tanto, también la función legislativa) no quedará interrumpido por la vigencia de estas situaciones de emergencia; extrayendo las mismas conclusiones de la remisión que hace a este precepto el art. 78.2, no cabe duda de que estaríamos ante idénticas Diputaciones «legislativas», y esta vez sin necesidad siquiera de mediación de decreto-ley alguno.

La incomunicación jurídica entre los arts. 78.2 y 86.3 de la Constitución priva, en consecuencia, de todo fundamento a cualquier pretensión de reconocer potestad legislativa a las Diputaciones Permanentes y sitúa justamente a la del Congreso en su enclave competencial propio (el que viene dado por el art. 86.2). Conviene, pese a todo, hacer algunas consideraciones adicionales que abundan en esta misma conclusión.

3. Argumentando en pro del reconocimiento de esta facultad, se ha dicho que, caso de no darla por buena, «se hurta a las Cortes la facultad de legislar sobre un tema (...) durante todo el período que dure la convocatoria electoral y la constitución de las nuevas Cámaras» ${ }^{28}$. Pero, precisamente durante todo este período, las Cámaras no existen. $O$, dicho más claramente: de los dos elementos básicos que integran la realidad de todo órgano del Estado - la competencia jurídicamente atribuida y el «sujeto portador del órgano»- no resta sino uno (la competencia, entendida como esfera ideal, no actual, de atribuciones) tras de la disolución de las Cámaras o la extinción de su mandato y hasta la «constitución de las nuevas Cortes Generales» (art. 78.3). Los sujetos que constituyen la base personal del órgano desaparecen jurídicamente con la disolución de la Cámara o al extinguirse su mandato (arts. 68.4 y 69.6 de la Constitución y 22.3 del Reglamento del Congreso), con la sola excepción de los miembros, titulares y suplentes, de la Diputación Permanente respectiva, que ven prorrogado su mandato hasta la constitución de la nueva Cámara (art. 22.3 del Reglamento del Congreso) y que siguen gozando de las prerrogativas propias de su cargo. Y con los miembros de las Cámaras desaparecen también, en rigor, los grupos parlamentarios, pese al impropio enunciado final del art. 78.1 de la Constitución y al menos aceptable aún del art. 57.4 del Reglamento del Congreso (según el cual la Diputación Permanente será convocada por su presidente «a petición de dos grupos parlamentarios»). Esto no significa otra cosa sino que, en nuestro Derecho, no existe (a salvo algún punto de no fácil interpretación en el artículo 116.5 de la Constitución) la institución de la prorogatio de las Cámaras, como recurso para garantizar la permanencia de las mismas hasta la constitución de las nuevas asambleas y el ejercicio de sus facultades de ordinaria administración y de intervención en situaciones excepcionales ${ }^{29}$. En el orde-

28 Cfr. E. Aja, ob. cit., pág. 134.

${ }^{29}$ Acerca de esta institución, en general, A. A. Romano, La prorogatio negli organi costituzionali, Milán, 1967, y P. Giocolo Nacci, «Prorogatio del Parlamento, mandato parlamentare e prerogative dei parlamentari», en Rassegna di Diritto Pubblico, núm. 3, 1964, págs. 700 y sigs. Agradezco al profesor G. Gómez Orfanell el haberme facilitado la consulta en este punto de su original de próxima publicación sobre «La prorogatio de los órganos constitucionales». 
namiento español - como en algunos otros en el Derecho comparado ${ }^{30}$-, la Diputación Permanente no puede considerarse, ni siquiera mediante una ficción jurídica, una «Cámara en prorogatio». Tampoco, disuelta la Cámara o expirado su mandato, es la Diputación Permanente - para decirlo con un concepto de G. Jellinek- órgano '«secundario» de aquélla y sí órgano en sí mismo, por más que con obvias peculiaridades y en una situación que - de acuerdo con A. Romano- puede calificarse como de suplencia ${ }^{31}$. Que las Diputaciones no se puedan identificar con sus respectivas Cámaras en prorogatio es algo que claramente se desprende de la diferenciación que la propia Constitución establece (art. 78) entre uno y otro órgano, así como de los poderes tasados de las primeras. Y ello tiene algunas consecuencias de importancia. En primer lugar, que las Diputaciones, por mandato de la Constitución, actúan en algunas competencias de las Cortes - del Congreso: artículos 86 y 116-, pero las ejercen como competencias propias y no como potestades delegadas o transferidas por las Cámaras; de ahí que la dación de cuentas recogida en el art. 78.4-y desafortunadamente redactada en el art. 59 del Reglamento del Congreso- no podrá tener, frente a lo que en algún caso se ha dicho, contenido de responsabilidad política ni menos aún podrá entenderse como referencia a una implícita condición resolutoria. En segundo lugar, que habrá que entender la enumeración de competencias en el art. 78.2 como numerus clausus, sin interpretación extensiva posible y a diferencia de lo que tiende a entenderse que ocurre en los casos de prorogatio (genérica habilitación para supuestos de «necesidad») ${ }^{32}$. Interpretación estricta de las competencias que se justifica, claro está, en la legitimación de segundo grado -representatividad atenuada - que ostentan los titulares del órgano y que sólo permite decisiones en sentido propio para los casos indiferibles expresamente invocados por la norma fundamental.

Seguramente, los propios antecedentes en nuestro Derecho histórico han llevado a desdibujar un tanto la configuración actual de las Diputaciones Permanentes como órganos de relevancia constitucional con funciones limitadas de suplencia. De institución «pseudo-tradicional» se las ha calificado en este sentido ${ }^{33}, y$ es lo cierto que resulta difícil reconocerles otras competencias

${ }^{30}$ Junto a órganos análogos en la vigente Constitución portuguesa (art. 182) y griega (art. 71), la Ley Fundamental de Bonn había incorporado en su art. 45 una Comisión Permanente (Ständiger Ausschuss) para «salvaguardar los derechos del Parlamento frente al Gobierno federal durante el período que medie entre los legislaturas». Esta Comisión (a la que expresamente se negaban potestades legislativas) fue suprimida por la Ley núm. 33 de Reforma Constitucional de 23-VIII-1976 (art. 1.3).

${ }^{31}$ Esta es la caracterización que da A. A. Romano (ob. cit., págs. 170-171) del órgano recogido en el art. 45 de la Grundgesetz hasta 1976 y aludido en la nota anterior. Sobre la suplencia en Derecho constitucional, cfr. A. Bozzi, Studi di Diritto costituzionale, Milán, 1961, pág. 60. El concepto de «órgano secundario» en G. Jellinek está expuesto en su Teoría general del Estado, ob. cit., pág. 414.

${ }^{32}$ Cfr. A. A. Romano, ob. cit., pág. 124.

${ }^{33}$ F. Rubio Llorente, artículo sobre «España» en Diccionario de Ciencia Política, Madrid, 1980, pág. 239. Sobre la Diputación Permanente en la historia del Derecho español, cfr. N. Pérez Serrano, La Diputación Permanente de las Cortes en nuestro Derecho constitucional bistórico, Madrid, 1932, y A. Monreal Ferrer, «Notas sobre las Diputaciones Permanentes del Congreso y del Senado», en Parlamento y sociedad civil, ob. cit., págs. 153 y sigs. 
—además de las propias del Congreso en el caso de los arts. 86.2 y 116 y de la convocatoria extraordinaria en el periodo entre sesiones- que no sean las hipotéticamente reconducibles a la ambigua expresión que es «velar por los poderes» de las Cámaras. En cuanto a esta fórmula, quizá no pueda decirse otra cosa - lo que no es poco, en definitiva-, sino que «velar por los poderes» no es ejercerlos y sí, parece, defender o proteger las competencias de que se trate. Defensa de las competencias que podría haber legitimado una previsión del legislador para el caso de conflictos constitucionales, que tal vez deba actuarse a partir de la llamada función «inspectiva» o inquisitiva -necesariamente diferenciada en este caso de la de control ${ }^{34}$ - y que, en última instancia, se adecúa bien a la naturaleza de las Diputaciones en el período entre legislaturas como órganos que aseguran, sí, la «continuidad» de las Cámaras, pero sólo si por tal se entiende la de una esfera de atribuciones constitucionales a preservar y a ejercer meramente en casos tasados.

Aunque es claro que no es éste el lugar para abordar más sistemáticamente la naturaleza de las Diputaciones Permanentes y el carácter de sus funciones en las diversas situaciones en que actúan - temas, por cierto, necesitados de una investigación en profundidad - sí puede concluirse, a partir de lo que se acaba de apuntar, en que los rasgos con que se perfilan estos órganos en nuestra Constitución impiden al intérprete considerarlos como manifestación de unas Cámaras en prorogatio. De ella deriva el que no sea posible tampoco entender ninguna genérica «subrogación» en aquéllas por lo que a las facultades de las Cortes se refiere.

4. Un enfoque finalista en la interpretación confirma, por lo demás, las conclusiones que vienen apuntándose. Los únicos casos en que las Diputaciones aparecen como órganos decisorios y activos en nuestro ordenamiento (ejercicio de competencias ex arts. 86.2 y 116) son claramente concesiones a la «necesidad» en la norma fundamental que -como se ha apuntado más arriba- aspiran a evitar la parálisis del Estado en situaciones muy cualificadas de emergencia. Pero en la atención de estas exigencias se agotan sus intervenciones «exteriores», y éste es todo el sentido que hay que ver en la remisión a aquellos preceptos en el art. 78.2. En este aspecto, las Diputaciones no están tanto al servicio de la continuidad funcional de las Cortes cuanto al de la continuidad misma del Estado como ordenamiento jurídico. $\mathrm{Y}$ no puede negarse que, una vez producidas aquellas intervenciones, la razón constitucional que lleva a estos órganos a actuar, con carácter extraordinario, facultades que ordinariamente son del Congreso se ha agotado. No hay más «necesidad» que la invocada por la norma del Derecho y ninguna parece que exista, en todo caso, para que las Diputaciones «prolonguen» su eficacia legitimante a través del ejercicio de potestades legislativas.

5. En algún caso, en fin, se ha querido encontrar en la institución de la descentralización legislativa (art. 75.2 y 3 de la Constitución) cierto argu-

${ }^{34}$ Sobre la posible legitimación de las Diputaciones para promover conflictos constitucionales en base al art. 73 y sigs de la LOTC, cfr. J. Bermejo Vera, «La función resolutoria de los conflictos constitucionales negativos por parte del Tribunal Constitucional», en El Tribunal Constitucional, vol. I, Madrid, 1981, pág. 596 (en nota). En cuanto a la caracterización de la función inquisitiva de las Cámaras, cfr. A. Pizzorusso, Lezioni di diritto costituzionale, Roma, 1981 , págs. 270 y sigs. 
mento para fundamentar tales potestades. Con independencia de las cautelas que en el terreno de la política legislativa merece esta técnica, y al margen también en este momento el muy incorrecto tratamiento de que ha sido objeto en el Reglamento del Congreso - regulación que considero inconstitucional ${ }^{35}$-, debe descartarse por completo tal pretendida interpretación. $Y$ no sólo porque la integración analógica esté impedida en el caso de competencias tasadas y excepcionales, sino también, y sobre todo, porque lo que se desprende del análisis del art. 75 en relación con el art. 78.2 es más bien el argumento a contrario. Esto es lo que, en efecto, deriva de la consideración de que nuestra norma fundamental sólo concibe la adopción de leyes formales por órgano distinto de la Cámara en pleno cuando la competencia es, en primer lugar, recuperable «en cualquier momento» por el órgano que ordinariamente la ostenta y cuando, en segundo término, ciertas materias - consideradas especialmente trascendentes - quedan excluidas de lo que llama «delegación» la Constitución. Ni una condición ni otra se dan, desde luego, en la hipótesis que se viene considerando. Disueltas las Cámaras o expirado su mandato, la sujeción que da la presencia del «delegante» desaparece por completo y se desvanece también la garantía que es el elenco de materias inafectables por la legislación del órgano «habilitado» con carácter extraordinario. Más aún: si se tiene en cuenta que las limitaciones materiales que rodean al decreto-ley (art. 86.1) desaparecen, como es claro, en el supuesto de que las Cámaras decidan acudir al procedimiento legislativo aludido en el apartado 3 del mismo precepto, la situación puede ser, si cabe, más absurda. Asumiendo, como se pretende, las Diputaciones la misma posición y competencia que las Cortes, ocurre que aquéllas podrán ya legislar sobre cualesquiera objetos, ya que la vía del art. 86.3 permite, desde luego, la introducción, en la ley elaborada a partir del «proyecto» por el que se tiene al decretoley, de normas innovadoras sin límite. No es necesario citar a este propósito un buen número de casos a lo largo de la Constitución en los que la sola hipótesis que se acaba de apuntar hace, en mi opinión, definitivamente inaceptable la tesis sobre la que en última instancia descansaría.

Por lo demás, si esta peculiar «potestad» legislativa queda prácticamente ilimitada en cuanto a su posible objeto de normación, no es menos grave la verosímil decadencia de las garantías propias al debate parlamentario a lo largo de su desenvolvimiento. El carácter de colegio restringido que define a las Diputaciones y, relacionado con ello, la relativa eficacia de la regla de la proporcionalidad que el art. 78.1 señala en cuanto a su modo de integración son datos que deben tenerse muy en cuenta para comprender en qué quedaría la posición de las minorías en el curso de aquel procedimiento.

${ }^{35}$ Me refiero a la presunción de delegación general que ha establecido el art. 148.1 del Reglamento - transformando la identidad misma del instituto de la «delegación» tal y como queda perfilado en el art. 75.2 de la norma fundamental-, así como a la limitación sin fundamento a que se ha procedido en el art. 149.1 respecto de la facultad del pleno para «recabar en cualquier momento el debate y la votación de cualquier proyecto o proposición que haya sido objeto de esta delegación» (art. 75.2). Para la práctica totalidad de la doctrina italiana - en cuyo Derecho se introdujo por vez primera esta técnica de la descentralización legislativa por la Ley fascista núm. 129, de 19-I-1939--, los efectos de la labor legislativa de las Comisiones no han sido en absoluto positivos (cfr. por todos T. Martines, Diritto costituzionale, Milán, 1978, págs. 307 y sigs.). 
Posición que - hay que subrayarlo- es cualitativamente distinta de la que puede producirse en el caso del procedimiento legislativo «descentralizado» y a la vista de las intervenciones plenarias que en este último supuesto ha garantizado la Constitución. La misma posibilidad de recurso ante el Tribunal Constitucional de una minoría parlamentaria (arts. 162.1.a de la Constitución y 32.1 de la LOTC) contra la ley hipotéticamente adoptada queda asimismo descartada. Es cierto que no habrá expirado el plazo de recurso cuando se constituyan las nuevas Cámaras (arts. 68.5 de la Constitución y 33 de la LOTC) y que aquí habría de ser decisiva la interpretación del propio Tribunal Constitucional en orden al cómputo del plazo, pero no deja de ser claro que la imposibilidad de recurrir inmediatamente contra la disposición legislativa adoptada contribuye a alterar, más aún, el sistema de relaciones entre mayoría y oposiciones. La misma regla de la publicidad, en fin, como norma sustantiva de valor relacionada con el concepto constitucional de ley (art. 80 de la norma fundamental) habría de quedar obviamente mediatizada; por más que el art. 58 del Reglamento del Congteso se remita a los criterios válidos en este punto para el pleno (art. 63), son patentes los límites a la publicidad que derivan de la propia estructura orgánica de las Diputaciones y del que debe ser su modo normal de trabajo.

Claro que si, tras de las consideraciones anteriores, la conclusión negativa acerca de las potestades discutidas parece clara, subsiste la pregunta política y la inquietud por las fundamentaciones reales que subyacen a los planteamientos criticados. El problema de la legitimación material de la decisión política —en el marco del sentido que informa a la norma constitucionaly el del concepto mismo de ley que pueda formularse a partir de aquélla son aquí cuestiones centrales que no pueden eludirse y de las que depende, en definitiva, la respuesta última en materia de fuentes del Derecho. Vale la pena, por tanto, seguir indagando por el significado de la ley en nuestro ordenamiento, así como por el carácter constitutivo que en la misma deben tener las condiciones de publicidad, deliberación y respeto de las minorías. Relativizar estas exigencias con el argumento de la innegable «crisis de la ley» en el Estado contemporáneo o señalando el cambio evidente en la función de oposición política no sería, en última instancia, sino reducir al ser el deber ser y abandonar con ello toda normatividad constitucional.

\section{ADDENDA}

Ya en imprenta las notas anteriores, se ha producido la publicación (Boletín Oficial del Estado de 28 de junio de 1982, núm. 153) de la sentencia número 29/1982, de 31 de mayo, del Tribunal Constitucional por la que se resuelve el recurso de inconstitucionalidad núm. 238/1981, promovido contra el Real Decreto-Ley 10/1981, de 19 de junio, sobre Inspección y Recaudación de la Seguridad Social. Hay en esta importante sentencia diversos pronunciamientos que contribuyen a delimitar la figura del decreto-ley en nuestro ordenamiento y a precisar el alcance de los varios controles constitucionales de los que el mismo puede ser objeto. Para la temática específica que se acaba de 
abordar - al margen otros aspectos que requerirían una atención aparte y en profundidad - son, en todo caso, relevantes las siguientes consideraciones del Tribunal:

1. En lo que se refiere a la relación entre los trámites previstos en los números 2 y 3 del artículo 86 se constata la práctica convencional hasta la fecha, según la cual uno y otro procedimiento quedan configurados como sucesivos, pero - y la salvedad me parece de la mayor trascendencia - admite también el Tribunal que «nada se opone a una interpretación alternativa de ambas vías, quedando este punto al criterio de oportunidad que pueda establecer en un futuro el Congreso de los Diputados» (Fundamentos Jurídicos, número 2). Parece apuntarse así -obiter dicta- a la plena constitucionalidad de una de las interpretaciones sostenidas en este trabajo, por más que no llegue el Tribunal, por no ser ello necesario para la fundamentación del fallo, a extraer más conclusiones de esta advertencia.

2. En lo relativo a la naturaleza del trámite de «convalidación» o «derogación» articulado en el número 2 del artículo 86 sí declara resueltamente el Tribunal que no estamos ante el ejercicio de potestad legislativa y que, en consecuencia, no queda convertido en ley el decreto-ley «convalidado» por el Congreso de los Diputados. Se afirma, efectivamente, en el mismo Fundamento 2 de la sentencia que «no puede considerarse que el decreto-ley se haya convertido en ley formal del Parlamento tras el acuerdo de convalidación, sino únicamente que se ha cumplido con el requisito constitucional del que dependía la pervivencia en el tiempo, con fuerza y valor de ley, de la disposición producto del ejercicio de la potestad normativa extraordinaria que al Gobierno le reconoce la Constitución. En otras palabras, el decreto-ley no se transforma en ley, es decir, no cambia su naturaleza jurídica». 